\title{
Evaluation of a multi-component and multi-agent intervention to improve classroom social relationships among early elementary school-age children
}

\author{
Francisco J. García Bacete ${ }^{\mathrm{a}, *}$, Ghislaine Marande ${ }^{\mathrm{a}}$, Amori Yee Mikami ${ }^{\mathrm{b}}$ \\ ${ }^{a}$ Department of Developmental, Educational, and Social Psychology and Methodology, Jaume I University, Castellón, Spain \\ ${ }^{\mathrm{b}}$ Department of Psychology, University of British Columbia, Vancouver, Canada
}

\section{A R T I C L E I N F O}

\section{Keywords:}

Peer relationships

Teacher-student relationships

Classroom intervention

\begin{abstract}
A B S T R A C T
We present the preliminary evaluation of a comprehensive, multi-component and multi-agent 2 year classroom intervention to enhance children's relationships with their peers and teachers among early elementary school students in Spain. The intervention contained universal components directed to the whole class plus targeted components for children with peer problems. Using a quasi-experimental design, 229 children (in 10 classrooms) formed a comparison group whose teachers engaged in their typical practices, followed the next year by 214 children (in 9 classrooms) who received the intervention. Children completed a sociometric procedure, and reported their self-perceptions of peer functioning and their relationship quality with teachers at the beginning of 1st grade (pretest) and the end of 2nd grade (posttest; 93\% retention). After statistical control of pretest functioning, by posttest those in the intervention group received fewer negative sociometric nominations, perceived themselves to receive fewer negative sociometric nominations and to have greater overall peer acceptance, and reported their teachers to have greater warmth and organization, compared to children in the comparison group. However, intervention group children also received fewer positive sociometric nominations (as well as perceived themselves to receive fewer positive nominations) than comparison group children. Target children, selected for being disliked by peers, received accentuated benefits from the intervention on the outcome variables of fewer negative nominations received and greater teacher warmth. Implications for practice are discussed.
\end{abstract}

Classroom social relationships carry long term effects on development for elementary school-age children. There is reason to be concerned about children who do not get along with classmates. Negative peer relationships predict children disliking school and withdrawing from participation, processes that result in poorer academic functioning after statistical control of earlier levels of achievement (Buhs, Ladd, \& Herald, 2006). Being disliked by peers also exacerbates children's externalizing and internalizing behaviors over time (Parker, Rubin, Erath, Wojslawowicz, \& Buskirk, 2006). Compounding the negative effects of difficulties with peers, children with peer problems often also have conflictual relationships with their teachers (Hughes \& Im, 2016). The consequences of poor teacher-student relationships can be additive with those from peer disliking in predicting the same adjustment outcomes (Hughes \& Chen, 2011). Collectively, this evidence underscores the importance of interventions to improve classroom social relationships, particularly for those children who are most at risk for adverse outcomes because they are disliked by peers at an early age.

\footnotetext{
* Corresponding author. Departamento de Psicología Evolutiva, Educativa, Social y Metodología, Universitat Jaume I, Castellón, Spain.

E-mail address: fgarcia@uji.es (F.J. García Bacete).
} 


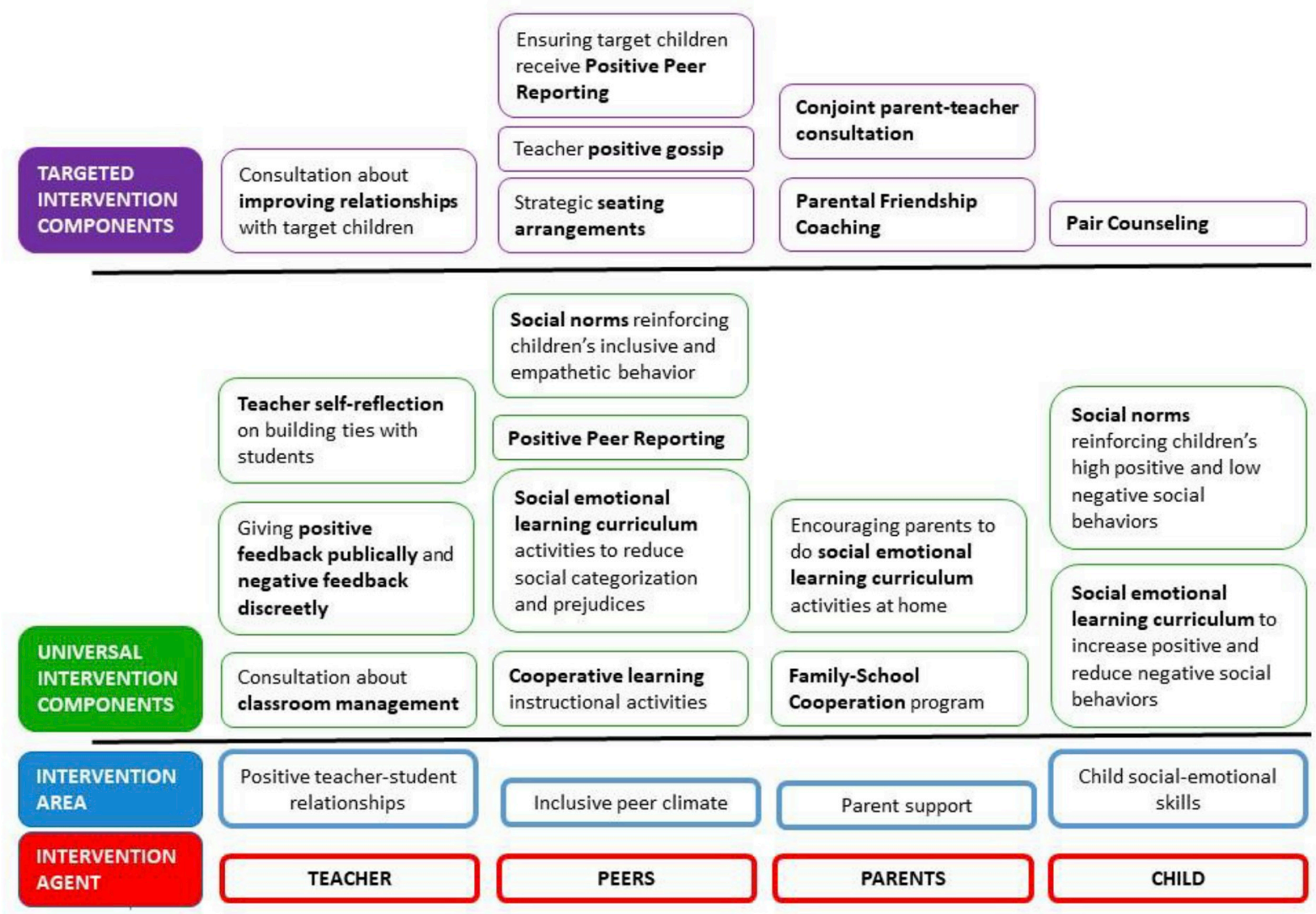

Fig. 1. The GREI intervention model.

Herein, we present the preliminary results from an intervention we designed and named after our research group, the GREI (Grupo Interuniversitario de Investigación sobre el Rechazo Entre Iguales; Interuniversity Research Group on Peer Rejection). The aim of the GREI intervention was to enhance positive relationships in the early elementary grades between Spanish children and their classmates and teachers, with a particular focus on children who are disliked by peers. A notable feature of this intervention is that we combined multiple empirically-supported approaches found in previous research to encourage children's positive social relationships. We report the results after the first 2 years (the 1st and 2nd grade years) among children who received intervention, relative to comparison children enrolled using a staggered design where the children in the comparison and intervention samples were consecutive 1 st grade cohorts at the same schools.

\section{The GREI model}

The theoretical model behind our intervention is that classroom social relationships are multifaceted, representing reciprocal interactions between children and peers, children and teachers, children and parents, and teachers and parents. Interactions between any one dyad produce ripple effects to the rest of the social system (Bronfenbrenner, 1992). For this reason, our intervention addresses four key areas that contribute to classroom relationships, involving multiple agents as targets of intervention, as illustrated in Fig. 1. Each area is described below.

Area 1: Child social-emotional skills. An important factor affecting whether children have good relationships is their social behavior and skills. Children who demonstrate cooperative behavior and good social cognitive skills, with low aggression and dysregulation, are favorably regarded by previously-unacquainted peers in new settings (Gifford-Smith \& Brownell, 2003). Interestingly, the presence of prosocial skills may be more relevant for being liked, whereas the absence of aggressive behavior may be more important for not being disliked by peers (Gifford-Smith \& Brownell, 2003).

Our intervention aimed to both encourage children's prosocial behavior and social cognitive skills as well as reduce children's disruptive and dysregulated behavior, via social-emotional learning curricula. This approach is supported by meta-analytic evidence, suggesting that school-based social-emotional learning curricula lead to increases in positive behaviors and reductions in negative behaviors (Durlak, Weissberg, Dymnicki, Taylor, \& Schellinger, 2011). Because our curriculum targeted changes in both positive and negative child behaviors, we expected this would result in children receiving more peer liking and also less peer disliking.

Area 2: Inclusive peer climate. Many interventions assume that if disliked children change their behaviors, then peers will 
notice and revise their unfavorable impressions (Mikami \& Normand, 2015). Following this conceptualization, the focus of most interventions for peer problems has been on the things children can do to help peers view them less unfavorably, while neglecting the things that help peers be more inclusive to children they dislike (Mikami \& Normand, 2015). Unfortunately, the pathway from children's social behaviors to peers' liking is not always straightforward. Peer groups have tendencies to mistrust and socially devalue classmates whom they perceive to be different (Chang, 2004). Therefore, children with different behaviors, even if these behaviors are harmless, may elicit peers' disliking (García Bacete, Carrero, Marande, \& Musitu, 2017). Second, once peers dislike a child, peers possess reputational biases where they pay selective attention to the negative behaviors of children whom they dislike while minimizing positive behaviors, and interpret ambiguous behaviors as negative (Peets, Hodges, \& Salmivalli, 2008). Collectively, these biases mean that even if disliked children reduce their negative behaviors (or increase their positive behaviors), peers may be cognitively predisposed to maintain their disliking.

Our intervention sought to help peers be inclusive toward children with behavioral differences, as well as to flexibly notice when disliked children change their behaviors to be less negative (or more positive). Addressing peers' biases toward disliked children could result in these children receiving more peer liking and less peer disliking; however, the empirical support for such approaches for reducing disliking may be stronger than that for increasing liking. For example, an intervention to create an inclusive peer group resulted in reductions in peers' disliking of target children with peer problems, but no change in peers' liking (Mikami et al., 2013).

Area 3: Positive teacher-student relationships. Teacher-student relationships that are high in warmth as well as in organization are suggested to enhance children's adjustment, including contributing to children displaying more positive and less negative social behaviors (Pianta \& Stuhlman, 2004). Therefore, they may reinforce the child social-emotional skills piece of our intervention (Area 1) to affect peers' impressions. Warm relationships between the teacher and students as a group also facilitate students' sense of classroom community (Wubbels, 2011), which can encourage bonds between children and reduce mistrust of classmates with behavioral differences. Further, when a teacher has a warm relationship with a student, this may encourage peers to view that student more favorably because the teacher is signaling that this student has value (Farmer, Lines, \& Hamm, 2011). As such, warm teacherstudent relationships may also assist with the focus of our intervention on building an inclusive peer climate (Area 2).

Our intervention therefore aimed to increase teachers' warmth and organization. Although these factors are expected to result in students receiving more liking as well as less disliking from peers, the evidence may be stronger for reducing peer disliking, for several reasons. First, teacher warmth, and teacher organization, appear more robustly linked to reducing children's oppositional behaviors relative to increasing children's prosocial behaviors (Collins, O'Connor, Supplee, \& Shaw, 2017; Levin \& Nolan, 2014). Reducing negative child behaviors may most directly affect peer disliking, since the most frequent reasons why children dislike classmates are negative behaviors such as aggression and disturbing others (García Bacete et al., 2017). This potentially implies a stronger pathway from teacher-student relationships to a reduction in peer disliking relative to an increase in peer liking. Second, teachers showing that they value disliked children may be most impactful on reducing those children's disliking by peers. Research in 5th grade classrooms found a stronger pathway between teachers' negative behaviors toward a student and classmates' subsequent disliking of that student, relative to the pathway between teacher positive behaviors and peers' liking of that student (Hendrickx, Mainhard, Oudman, Boor-Klip, \& Brekelmans, 2017). Relatedly, a longitudinal study with children from 1st to 4th grade found that the teacher-student relationship affected peer disliking but not peer liking (Hughes \& Im, 2016).

Area 4: Parent support. When a parent and teacher have good communication, this is suggested to enhance the child's positive behaviors and reduce negative behaviors (El Nokali, Bachman, \& Votruba-Drzal, 2010), and may encourage teachers to have more positive relationships with that child (Hughes \& Kwok, 2007). In addition, if parents coach their young children to display better social behaviors as well as arrange opportunities (e.g., playdates) for children to learn and practice social skills, this may result in children being viewed more favorably by peers at school (McDowell \& Parke, 2009). Therefore, we view parent support as facilitating the child social-emotional skills piece of our intervention (Area 1), as well as improving the teacher-student relationship (Area 3), to the ultimate goal of improving peer relationships in the classroom.

We included intervention components to target parent support to this end. Because parental coaching in our intervention focuses on helping children to make and keep friends through increasing prosocial behaviors (Mikami, Lerner, Griggs, McGrath, \& Calhoun, 2010), results may be seen in peer liking, given the ties between positive behaviors and liking (McDowell \& Parke, 2009). On the other hand, if parent-teacher communication improves the teacher-student relationship, this may have greater effects on reducing peer disliking as described in Area 3.

Multi-component and multi-agent intervention. Fig. 1 shows that the GREI intervention contains components addressing each of these areas thought to contribute to classroom social relationships. Further, it involves teachers, parents, peers, and children as agents of change.

Our overarching goal was to draw from all available approaches with empirical support to comprehensively improve children's classroom relationships. Although a downside is that it resulted in us being unable to test the relative efficacy of each intervention component, we chose this approach for several reasons. First, each GREI intervention component has some empirical support already individually. Second, we aspired to create an intervention with the greatest potential for efficacy, and the uniqueness of our intervention is in its combination of approaches to hopefully maximize impact. Existing interventions often have limited effects on peer liking and disliking (Mikami \& Normand, 2015). As one example, the FAST Track intervention (involving 7560 children; 845 were a high-risk sample with conduct problems), found intervention effects on peer liking and disliking for high-risk children only and not for the classmates of these children after 1 year of intervention (Conduct Problems Prevention Research Group, 1999a; 1999b), and no effects after 3 years of intervention (Conduct Problems Prevention Research Group, 2002). Researchers have speculated that the difficulty in changing peer liking and disliking may be attributable to these constructs being affected by multiple agents (children's behaviors, peers' reputational bias against disliked children, teachers' practices, parents' actions); see Parker et al. (2006). Precisely 
for this reason, we designed the GREI intervention to target these multiple contributors.

In addition, research supports the utility of universal classroom interventions applied to all students, to promote social-emotional development (January, Casey, \& Paulson, 2011). On the other hand, certain children, for instance those with peer problems, need more intensive or directed intervention and do not adequately benefit from universal approaches alone (Kaufman, Kretschmer, Huitsing, \& Veenstra, 2019). Children who are disliked by classmates are most likely to be showing negative behaviors, to have poor relationships with teachers, and to elicit peers' reputational biases that prevent peers from revising their impressions even in the presence of disconfirming evidence (Mikami \& Normand, 2015). For this reason, the GREI intervention follows a model used in other classroom interventions to improve social competence (e.g., Conduct Problems Prevention Research Group, 1999a; 1999b) and consistent with school psychology practice guidelines (National Assocation of School Psychologists, 2016), where it contains aspects that are delivered universally to the whole class, plus more intensive aspects directed to target children who are disliked by peers. As seen in Fig. 1, there are universal and targeted components in each of the four intervention areas. Finally, we elected to begin the intervention in the 1st grade, given the developmental importance of establishing good social relationships early in elementary school (January et al., 2011).

We note that the cultural context of early elementary school in Spain, including the determinants of peer liking and disliking, is largely similar to that of North America. For example, the reasons given by 1st and 2nd grade children in Spain for why they dislike classmates reflect children's perceptions of their classmates' negative behaviors such as aggression and disturbing others, and, to a lesser extent, fear and mistrust of what is unfamiliar (García Bacete et al., 2017). Because of the similarity of peer processes between Spanish and North American children, we have drawn from intervention approaches in North America when developing the GREI intervention.

\subsection{The current study}

The GREI intervention was designed as a multi-component and multi-agent program to improve early elementary school students' classroom social relationships, with a particular focus on children who are disliked by peers. Using a quasi-experimental, staggered implementation design, all the 1st grade students in four elementary schools in Spain formed a comparison group that entered the study 1 year before the students in the intervention group (who were all the 1st grade students in the same schools the following year). The current paper presents the preliminary results after 2 years of intervention (spanning the beginning of 1st grade through the end of the 2nd grade). During this period, all students in the GREI intervention group received the universal components of the intervention and target children selected for being disliked by peers received additional components containing higher doses of the intervention.

Our primary aim was to investigate whether children received more peer liking and less peer disliking in the GREI intervention group, relative to in the comparison group. Peer reports of liking and disliking from sociometric interviews were our primary outcome measures as they are often considered to be the gold standard (Cillessen \& Bukowski, 2018). Our second aim was to investigate whether similar outcomes in the intervention relative to comparison groups were obtained on children's self-perceptions of the extent to which peers liked and disliked them, as well as of their overall peer acceptance. Self-perceptions of peer relationships were important to examine because they uniquely relate to adjustment, above and beyond the effects of peer reports (García Bacete, Marande, Schneider, \& Cillessen, 2019). Our third aim was to examine intervention versus comparison group differences on children's perceptions of their teacher as warm as well as organized. We viewed teacher-student relationships as a factor that supports children's liking and disliking by peers, and also as part of characterizing positive classroom social relationships for young children. Our final aim was to investigate whether target student status moderated the effects of the GREI intervention. Target students represent an atrisk group who were offered higher, more intensive doses of the intervention. As such, we theorized that they would receive accentuated benefit from the GREI intervention relative to non-target students.

\section{Method}

\subsection{Participants}

Participants were 443 children in Castellón (Spain), attending four mainstream public schools located in urban areas and primarily serving families of middle socio-economic status. Of these participants, 229 children (nested in 10 classrooms) composed a comparison sample which represented all of the 1st grade classrooms in these four schools. An intervention sample of 214 children (nested in 9 classrooms) represented all of the 1st grade classrooms in the same four schools the following year that the comparison participants were enrolled. As depicted in Table 1, the sample represented typical 1st grade children in Spain (51.5\% male; mean age 6.4 years, 95.6\% white), with no differences on these variables in the comparison and intervention groups (all $p s>.05$ ).

Ninety-one of the 443 children in the full sample were designated as target children because they were disliked by peers, with 44 in the comparison group and 47 in the intervention group; this difference was not significant $\left(\chi^{2}(\mathrm{df}=1)=0.328 ; p=.567\right)$. Target children were majority male (65.9\%), but otherwise reflected the age and ethnic breakdown of the full sample (see Table 1).

In Spain, children typically have the same teacher and classmates in the 1st and in the 2nd grade. (They switch to another teacher for the 3rd and 4th grade, and to another teacher for the 5th and 6th grade). As such, participants entered our study in the 1st grade and they continued with the same teacher in 2 nd grade. Therefore, the teachers in the comparison sample were all different individuals from the teachers in the intervention sample. Comparison teachers were 3 males and 7 females with an average of 15.2 years of teaching experience; intervention teachers were 9 females with an average of 15.0 years of experience. Neither gender $\left(\chi^{2}\right.$ 
Table 1

Descriptive statistics of the sample.

\begin{tabular}{|c|c|c|c|c|c|c|c|c|}
\hline & \multicolumn{4}{|c|}{ Full Sample $(N=443)$} & \multicolumn{4}{|c|}{ Target Children $(N=91)$} \\
\hline & Intervention & & Comparison & & Intervention & & Comparison & \\
\hline$\%$ Male & 47.20 & & 50.22 & & 68.10 & & 63.60 & \\
\hline$\%$ White & 96.98 & & 94.29 & & 97.10 & & 92.30 & \\
\hline \multirow[t]{3}{*}{ Age (months) } & 76.30 & & 76.39 & & 76.40 & & 76.15 & \\
\hline & Pretest & Posttest & Pretest & Posttest & Pretest & Posttest & Pretest & Posttest \\
\hline & $M(S D)$ & $M(S D)$ & $M(S D)$ & $M(S D)$ & $M(S D)$ & $M(S D)$ & $M(S D)$ & $M(S D)$ \\
\hline $\begin{array}{l}\text { Positive nominations } \\
\text { received }\end{array}$ & $27.05(12.94)$ & $19.98(11.61)$ & $21.52(11.74)$ & $26.08(14.34)$ & $16.50(13.20)$ & $12.12(10.08)$ & $10.43(7.13)$ & $15.30(11.64)$ \\
\hline $\begin{array}{l}\text { Negative nominations } \\
\text { received }\end{array}$ & $16.50(14.32)$ & $6.62(8.85)$ & $14.54(15.06)$ & $13.54(13.05)$ & $34.93(20.87)$ & $18.30(14.47)$ & 36.09 (19.04) & $29.10(15.68)$ \\
\hline $\begin{array}{l}\text { Positive nominations } \\
\text { expected }\end{array}$ & $19.12(11.50)$ & $16.59(11.71)$ & $19.46(11.16)$ & $21.22(10.86)$ & $18.14(13.06)$ & $10.96(11.40)$ & $20.65(12.52)$ & $17.24(10.12)$ \\
\hline $\begin{array}{l}\text { Negative nominations } \\
\text { expected }\end{array}$ & 12.34 (13.39) & $4.36(6.90)$ & $12.18(1090)$ & $11.69(10.54)$ & $17.17(21.50)$ & $4.14(7.55)$ & $16.85(14.15)$ & $13.02(12.78)$ \\
\hline $\begin{array}{l}\text { Self-perceived peer } \\
\text { acceptance }\end{array}$ & $3.41(0.53)$ & $3.56(0.49)$ & $3.37(0.51)$ & $3.33(0.52)$ & $3.33(0.62)$ & $3.57(0.52)$ & $3.27(0.74)$ & $3.35(0.60)$ \\
\hline Teacher warmth & $4.05(0.58)$ & $4.11(0.58)$ & $4.30(0.39)$ & $3.84(0.74)$ & $4.00(0.74)$ & $3.96(0.68)$ & $4.36(0.36)$ & $3.51(0.84)$ \\
\hline Teacher organization & $4.17(0.48)$ & $4.19(0.46)$ & $4.16(0.50)$ & $3.97(0.59)$ & $4.18(0.62)$ & $4.14(0.54)$ & $4.22(0.49)$ & $3.83(0.50)$ \\
\hline
\end{tabular}

$(\mathrm{df}=1)=3.206 ; p=.073)$ nor experience $(t(17)=0.044 ; p=.965)$ significantly differed between comparison and intervention group teachers.

\subsection{Procedure}

Parents, teachers, and principals provided written informed consent, and children assented to study procedures. All procedures were approved by the ethics board of the university, the school boards associated with the participating schools, and the Department of Education of the Regional Government of Valencia (Spain) in which Castellón is located.

Timeline. Parents of all 1st grade students at the four participating schools were informed about the study at the beginning of their child's 1st grade year. All but two eligible families (443/445) agreed to participate. In the fall of the 1st grade (pretest assessment), we collected study measures assessing peer liking and disliking through sociometric measures, children's self-perceptions of their peer liking and disliking and overall peer acceptance, and children's perceptions of their teachers' warmth and organization. Teachers in the comparison sample engaged in their typical practices during the 1st and 2nd grade years, whereas teachers in the intervention sample were asked to administer the GREI intervention during the 1st and 2nd grade years. At the end of the 2nd grade year (posttest assessment) we administered the same study measures as we did at pretest. At the posttest assessment we obtained data from 413 of the original 443 children in the full sample (and 83 of 91 target children), which is a 92-93\% retention rate across the 2year study period. Missing data were, in all cases, attributable to children changing schools between the 1st and 2nd grade year.

Intervention and comparison group assignment. In the first year of the study, all the 1st grade classrooms at the four participating schools became the comparison sample. Comparison group teachers followed whatever typical practices and professional development in which they would normally engage during the children's 1st and 2nd grade years. One year after the comparison children began the study (and had graduated from 1st grade, and moved on to 2nd grade), all the 1st grade classrooms at these same four schools became the intervention sample. We provided intervention group teachers with training in the GREI intervention during the children's 1st and 2nd grade years.

We recognize the limitations of this study design relative to true random assignment. However, this quasi-experimental design was most feasible and palatable for schools, and allowed us to maximize recruitment and retention. Although the comparison cohort and the intervention cohort cannot be fully compared because assignment to groups was not randomized, child and teacher demographics were similar in both samples (see Table 1), and our hope is that the school context was also similar across samples with the exception of the GREI intervention. The 1-year lag between the comparison and the intervention conditions, and the fact that teachers worked in grade level teams as opposed to across grade levels, are factors that hopefully reduced the potential for contamination from the intervention group teachers to the comparison group teachers.

Selection of target students. We identified a total of 91 children as target students using a combination of rejected sociometric status and teacher nominations. Specifically, the following procedure was used: In the fall of the 1st grade year (pretest assessment), 56 children became targets because they were classified as peer-rejected based on peer sociometric nominations (see Measures). At the same timepoint we asked teachers standardized questions soliciting their nominations of any children for whom the teacher had "significant concerns" about their peer problems; this yielded another seven children designated as targets who had not been classified as peer-rejected (although most were neglected or controversial status). These 63 students received targeted intervention components in their 1st grade year if they were in the intervention group, and they received teachers' typical practices if they were in the control group. 
In spring of 1st grade and fall of 2nd grade we again administered the sociometric procedure and solicited teacher nominations of children with peer difficulties. Of the children identified as targets initially, slightly over half (56\%) remained targets based on continued rejected sociometric status or teacher nominations. Further, an additional 28 children were identified as new targets based on peer-rejected sociometric status; no children were identified as new targets based on teacher nominations. (Note that no sociometric procedure was conducted in fall of 2nd grade with the comparison group, which was an oversight, but we solicited teacher nominations of target children at this timepoint). For intervention group children identified as targets in the fall of 1 st grade who received targeted intervention components in their 1st grade year, if they had normalized peer status after the 1st grade then we withdrew the augmented intervention components in the 2nd grade. On the other hand, children who were targets in 1st grade and continued to be targets in 2nd grade, as well as new targets in 2nd grade, were given the augmented intervention components in the 2nd grade.

For the purpose of our data analysis, we consider any child in the target sample if they were designated as a target in 1 st grade (56 from peer-rejected status plus 7 from teacher nominations - about half of whom continued to be targets in 2nd grade) or newly in 2nd grade (28 from peer-rejected status and 0 from teacher nominations). This yields our final target student sample of 91.

\section{GREI intervention description}

Overview. The intervention consisted of 9 weeks of activities delivered to children in the 1st grade and 18 weeks of activities in the 2nd grade. In both 1st and 2nd grade years, there were universal intervention components offered to the whole class (non-target and target children), and targeted components representing more intensive efforts directed toward the target children.

Training. In the first part of each school year (before intervention activities were initiated), teachers received training in intervention techniques. In the 1st grade year, this consisted of six, 90-min group meetings between teachers and the research team to discuss and practice each intervention component, as well as to handle organizational issues. In the 2nd grade year, this consisted of seven group meetings of $120 \mathrm{~min}$ each. To provide ongoing support to teachers, once intervention provision started the research team had biweekly individual 1-h consultation sessions with each teacher during the school year. This resulted in five individual consultation sessions in the 1 st grade year and 10 sessions in the 2nd grade year.

Universal components. As shown in Fig. 1, the GREI intervention contained content to address each of the four areas thought to contribute to positive classroom social relationships. The intervention components that were universal, that is, delivered to the whole class, are listed below.

Area 1: Child social-emotional skills. We instituted a social-emotional learning curriculum for students based on two prominent models of social-emotional intelligence (Bar-On, 2006; Rose-Krasnor \& Denham, 2009). The curriculum contained lessons on prosocial behavior, assertiveness, emotion recognition and regulation, and interpersonal problem solving. Teachers were provided with booklets containing detailed activities (full content of dialogs, role-plays, etc.) and instructions for implementation. The teacher was asked to deliver two lessons weekly (of 40-50 min each) during the school day, which consisted of didactic content combined with skills practice including role-playing and modelling. To facilitate children's generalization of skills to their day-to-day interactions, the teacher set social norms to encourage students to identify and label their emotions (and emotions of peers) in real time, and assisted students in applying the problem solving skills during real life peer conflicts by using the reminder "talk it out." Teachers were also instructed to call positive attention to children's displays of social-emotional skills during the school day to reinforce this behavior.

Area 2: Inclusive peer climate. The teacher can be a powerful force in not only facilitating children's socially skilled behavior, but also encouraging children's inclusive treatment of others and flexible social judgments about classmates who they perceive to be different. Therefore, as part of the social-emotional learning curriculum, the teacher also delivered instructional content regarding children demonstrating kindness to others who are different (e.g., by reading and discussing a story about a child who does not fit in), and had children practice inclusive, empathetic behavior by saying "I put myself in your shoes". Teachers helped children generalize inclusive behavior to their day-to-day interactions by introducing social norms in the classroom such as "you can't say you can't play", an approach empirically supported to reduce social exclusion in young children (Harrist \& Bradley, 2003). Some content in the socialemotional learning curriculum also directly taught children to be aware of their prejudices and biases. Further, the teacher conducted Positive Peer Reporting, a technique containing structured sessions during which peers had the opportunity to recognize positive characteristics in classmates, which is suggested to improve sociometric outcomes (Morrison \& Jones, 2007). Cooperative learning instructional methods have also been found to benefit students' peer relationships, because they build bonds between peers and send the message that every student has value (Roseth, Johnson, \& Johnson, 2008). As such, we encouraged teachers to divide their students into cooperative teams of four children, and to change teams over the course of the year. Every week, we recommended that teachers conduct two cooperative learning activities, such as those described in Kagan and Kagan (2009) and Pujolàs (2008).

Area 3: Positive teacher-student relationships. We targeted two dimensions of good teacher-student relationships: warmth (characterized by emotional support) and organization (characterized by structure and proactive behavior management; Wubbels, 2011). We followed a training plan (Korpershoek, Harms, de Boer, van Kuijk, \& Doolaard, 2016), in which we first aimed to make teachers aware of their own preferences, expectations, and biases, while helping teachers self-reflect on ways to develop positive bonds with all students. Then, content focused on teachers' classroom management, such as how to communicate behavioral expectations, reinforce student displays of desired behavior, and handle misbehaviors (Levin \& Nolan, 2014). We encouraged teachers to give positive feedback publicly and negative feedback discreetly to students, a technique associated with preventing students' negative sociometric outcomes (Mikami \& Mercer, 2017).

Area 4: Parent support. We implemented the Family-School Cooperation training program (Forest \& García Bacete, 2006) which 
helps teachers increase their positive communication with parents to collaboratively identify the child's educational issues, develop ways to support the child, and monitor progress. In addition, teachers were encouraged to send information home about the socialemotional skills curriculum being delivered, so that parents could practice the activities with their children to enhance generalization.

Targeted components. As shown in Fig. 1, within each of the four areas we also delivered strategies directed toward target children. The purpose was to provide a higher intervention dose to these target children than they were already receiving from the universal components.

Area 1: Child social-emotional skills. We applied Pair Counseling in the school context (García Bacete, Rubio, Milián, \& Marande, 2013; Karcher, 2007) to bolster the social skills of target children. Children received six to eight sessions of the program, with the goal of helping them to learn perspective taking and negotiation strategies, and to reduce negative behaviors. Each session consisted of 45min of activities in a pair consisting of a target child and a peer the same age and sex as the target child, with a facilitator who was a study staff member. Most pairings were between target children from different classrooms, but occasionally non-target children were placed in the pair if they were perceived to be the best match for the target child; see García Bacete et al. (2013). The goal was for target children to learn and practice social skills, with adult coaching.

Inclusive peer climate. Based on findings that being associated with higher status children may help peers change their impressions of children who they dislike, we adopted practices from studies that have manipulated classroom seating arrangement as an intervention for disliked children (van den Berg \& Stoltz, 2018). Specifically, we instructed teachers to plan their classroom seating arrangements by placing each target child with peers who were sociometrically preferred or average, and who had not negatively nominated the target child in the sociometric interview. Further, although teachers introduced Positive Peer Reporting with the whole class (Morrison \& Jones, 2007), they were instructed to strategically ensure that target children were chosen to receive compliments from peers. In order to help peers overcome existing reputational biases against children whom they dislike, we also asked the teacher to introduce "positive gossip" about target children. In this strategy, the teacher might relate to peers that the target child was good at something (e.g., knowing about bugs; willing to show their sticker collection; always having a wonderful smile), with the intent to alter peers' impressions about target children (Mikami et al., 2013).

Area 3: Teacher-student relationships. Positive relationships with teachers are suggested to have accentuated influence on improving peers' sociometric impressions about children with behavior problems, because peers most look to the teacher for cues about how to judge these children (Mikami, Griggs, Reuland, \& Gregory, 2012). However, children who are disliked by peers often have difficult behaviors that also impede good relationships with teachers (De Laet et al., 2014). As such, the consultation sessions with teachers as part of the universal component to improve teacher-child relationships contained designated activities to generate better relationships with target children who may be more difficult for teachers to like. For example, teachers completed a worksheet to identify positive attributes in target children, brainstorm about when the teacher might notice these attributes, and track when the teacher pointed out positive attributes.

Parent support. We adapted the Parental Friendship Coaching program (Mikami et al., 2010) to teach parents methods to help their children develop better friendships. Study personnel delivered the program in eight, 90-min workshops held weekly. Content focused on helping parents improve communication with their children so that children are more receptive to parents' suggestions, coaching children to display friendship skills in peer settings (such as how to be a good sport), and arranging supervised playdates so that children have opportunities to practice friendship skills. Teachers also offered parents of target children up to four additional parent-teacher consultation meetings to facilitate a collaborative plan to address the child's social and behavioral needs. We adapted strategies used in the conjoint behavioral consultation procedure (Sheridan \& Kratochwill, 2007), whereby these parent-teacher meetings were attended by a facilitator who asked both parties structured questions regarding their concerns about the child and their ideas about what might address these concerns. The facilitator suggested exercises to help the parent and teacher develop a shared plan to address children's difficulties.

Implementation fidelity. Across the 2 years of the study, the majority of intervention group teachers (7 of 9) attended all 13 training sessions. The remaining two teachers each attended 11 of the 13 possible training sessions. All teachers attended 15 of 15 possible individual consultation sessions with the research team once the implementation of the intervention activities began.

We provided a chart to each teacher outlining the intervention activities that teachers were asked to implement, broken down by week. These included all universal intervention components, and most targeted components (with the exception of Pair Counseling and Parental Friendship Coaching, which were delivered by study personnel). Whenever the teacher met with the study staff member for consultation (every other week), the staff member inquired about each activity on the chart and recorded the teacher's report of whether the teacher completed that activity. If teachers expressed having inadequate time to deliver an activity, our staff brainstormed ways to make delivery feasible. Using this procedure, teachers self-reported completing $100 \%$ of intervention activities that were intended to be delivered by the teacher. We concur with the teachers' report that implementation integrity was high based on our unstructured observations during the consultation sessions. For instance, it was possible to verify that the teacher had changed seating arrangements, or to view the social emotional learning curriculum lessons on the wall during consultation. Teachers also showed us examples of cooperative learning activities they implemented, or the social emotional learning activities children had done at home. Nonetheless, we do not have other measures of implementation, such as independent observations of teacher behaviors. Nor do we have measures of the quality with which teachers enacted each of these intervention strategies.

In regards to the components delivered to target children by study personnel (as opposed to by teachers), $97 \%$ of the children offered Pair Counseling attended all sessions. In addition, $67 \%$ of the parents of the target children who were offered Parental Friendship Coaching attended at least one session of the program (43\% attended at least seven of the eight sessions). The Pair Counseling and Parental Friendship Coaching sessions were videotaped, and our study team reviewed them in order to provide 
supervision and guidance to the facilitators; however, we do not have formal measures of facilitators' adherence to the content of any sessions.

Finally, on a survey containing nine questions regarding satisfaction with the intervention and perceptions of intervention utility, $100 \%$ of teachers rated all questions as either a 3 or 4 (on a Likert scale from $1=$ Poor to $4=$ Excellent). We do not have measures of parents' or children's satisfaction.

\section{Measures}

All measures were administered in private, individual interviews where a trained study staff member read the items aloud to the child and wrote down the child's answers. The accuracy of the instruments translated from English was verified by a back-translation procedure.

Peer sociometric nominations received. Children participated in a sociometric nomination procedure (Coie, Dodge, \& Coppotelli, 1982) where they were asked to nominate classmates whom they liked, and then whom they disliked. Sociometric nominations have been extensively used, with high test-retest reliability, associations with teacher and self-perceptions of peer relationships, and predictive validity for future adjustment (Cillessen \& Bukowski, 2018). Children were permitted to make an unlimited number of nominations (or no nominations) for each question. For each child, we calculated a proportion score of Positive Nominations Received, reflecting the number of liked nominations the child received divided by the number of classmates making nominations and multiplied by 100 . We similarly calculated a proportion score of Negative Nominations Received, reflecting the number of disliked nominations the child received divided by the number of classmates making nominations and multiplied by 100 . These variables were the primary outcome measures.

We additionally used the sociometric nominations to classify children into categories of average, preferred, rejected, neglected, and controversial status (García Bacete \& Cillessen, 2017). To calculate the cutoffs for each status group, we computed continuous binomial probabilities of positive (POS) and negative (NEG) nominations received in each classroom. Based on $t$-values linked to asymmetry indices and a probability level of 0.05, using Salvosa's tables, upper and lower limits were set for positive nominations ( $U L_{P O S}$ and $L_{P O S}$ ) and negative nominations ( $\mathrm{UL}_{\mathrm{NEG}}$ and $\mathrm{LL}_{\mathrm{NEG}}$ ) relative to the mean of nominations received ( $\mathrm{M}_{\mathrm{POS}}$ and $\mathrm{M}_{\mathrm{NEG}}$ ). See González and García Bacete (2010a) for details. A child was classified as preferred when POS $\geq \mathrm{UL}_{\mathrm{POS}}$ and NEG < $\mathrm{M}_{\mathrm{NEG}}$; rejected when NEG $\geq \mathrm{UL}_{\mathrm{NEG}}$ and POS $<\mathrm{M}_{\mathrm{POS}}$; neglected when POS $\leq 1$ (in case of 5 or unlimited nominations the value should be the largest value of $L_{\mathrm{POS}}$ or 1 ) and $\mathrm{NEG}<\mathrm{M}_{\mathrm{NEG}}$; controversial when either [POS $\geq \mathrm{UL}_{\mathrm{POS}}$ and $\mathrm{NEG} \geq \mathrm{M}_{\mathrm{NEG}}$ ] or $\left[\mathrm{NEG} \geq \mathrm{UL}_{\mathrm{NEG}}\right.$ and $\mathrm{POS} \geq \mathrm{M}_{\mathrm{POS}}$; t the remaining children were average. The rejected category determined who was identified as a target child. Calculations were made with the Sociomet software (González \& García Bacete, 2010b).

Peer sociometric nominations expected. In the same sociometric procedure, after children provided positive and negative nominations about classmates, we also asked children to name the peers they thought liked them and which ones did not. Positive Nominations Expected and Negative Nominations Expected represent the number of peers the child expected to have nominated him or her positively (or negatively, respectively), divided by the number of peers eligible to make nominations and multiplied by 100 . These variables measure children's perceptions of their peer liking and disliking. This construct, often referred to as dyadic metaperception, has been established to be an important part of children's social cognition in the peer relationships literature, and to relate to adjustment (Bellmore \& Cillesen, 2003). These two variables were secondary outcomes.

Self-perceptions of peer acceptance. We administered the Peer Acceptance subscale of the Pictorial Scale of Perceived Competence and Social Acceptance for Young Children (Harter \& Pike, 1984). This is a measure of children's overall self-perceptions of peer acceptance (to distinguish it from their specific perceptions of which classmates nominated them positively and negatively). Children responded to six items answered on a 4-point scale, where they reported, for instance, the extent to which they get asked versus not asked to play with others. High scores on this continuous measure represent children's self-perceptions that peers like them, whereas low scores represent self-perceptions that peers dislike them. This measure is widely used in the research literature and shows strong test-retest reliability and construct validity (Harter \& Pike, 1984). Cronbach's $\alpha$ in our sample was .77 at pretest and .81 at posttest. This measure was also a secondary outcome variable.

Teacher-child relationships. As another secondary outcome, children reported their perceptions of the teacher on the Questionnaire on Teacher Interaction-Early Primary (Zijlstra, Wubbels, Brekelmans, \& Koomen, 2013), validated in a Spanish population (García Bacete, Marande, Ferrá, \& Monjas, 2014). Children responded on a 5-point Likert scale (1 = never occurs; $5=$ always occurs) about behaviors of their teacher. The first dimension assessed was teacher warmth, measured by the Teacher Affiliation subscale (8 items; e.g. "The teacher acts friendly toward children") and tapping warm, positive, and emotionally supportive relationships between teachers and students. The second dimension assessed was teacher organization, measured by the Teacher Control subscale (10 items; e.g. "The teacher explains everything well”) and tapping teachers' use of structure, organized classroom routines, and proactive behavioral management strategies. Internal consistency was acceptable in our sample (pretest $\alpha=.71$ and .70 in warmth and organization respectively; posttest $\alpha=.78$ and .70, in warmth and organization respectively). These subscales have been found to predict children's academic achievement (García Bacete et al., 2014).

\subsection{Data analytic strategy}

We conducted Hierarchical Linear Modelling analyses (HLM; Raudenbush \& Bryk, 2002) using a two level model with children (Level 1) nested in classrooms (Level 2) which reflected the nested structure of the data. For each outcome variable (assessed at posttest), we created a model with the pretest value of that same variable as a covariate at Level 1. Target child status (dichotomous, 
dummy coded) was entered as a predictor at Level 1 . We did not include any demographic covariates because, as shown in Table 1 , no demographic variable differed between the intervention and comparison groups. Missing posttest data, affecting $7 \%$ of the full sample and $8 \%$ of the target sample, were handled via listwise deletion. The intraclass correlations (ICCs) representing the proportion of variance at Level 2 in unconditional models with only the pretest measure and target child status as predictors of the same posttest measure were generally high (see Table 3), suggesting the necessity of using HLM (Raudenbush \& Bryk, 2002).

We created a model for each of the seven posttest variables (positive nominations received, negative nominations received, positive nominations expected, negative nominations expected, self-perceived peer acceptance, teacher warmth, teacher organization). We first tested the main effect of the GREI intervention on the posttest outcome by placing intervention condition ( $\gamma_{01}$; GREI versus comparison group) as a Level 2 predictor of the intercept of the posttest variable. Then, we added the cross-level interaction between intervention condition and target child status to examine whether the effects of the GREI intervention differed for target relative to non-target children. We note that we reconducted analyses with only sociometrically rejected children as targets $(n=84)$, omitting the seven children who became targets because they were nominated by teachers as having peer problems. Results were unchanged, so we have retained the 91 target children in analyses. Thus:

$$
\begin{gathered}
\text { Level 1:POSTTEST } T_{i j}=\beta_{0 j}+\beta_{1 j}\left(\text { PRETEST }_{i j}\right)+\beta_{2 j}\left(\text { TARGET }_{i j}\right)+r_{i j} \\
\text { Level } 2: \beta_{0 j}=\gamma_{00}+\gamma_{01}\left(\text { INTERVENTION }_{j}\right)+u_{0 j} \\
\beta_{1 j}=\gamma_{10} \\
\beta_{2 j}=\gamma_{20}+\gamma_{20}\left(\text { INTERVENTION }_{j}\right)
\end{gathered}
$$

The study classrooms were nested in four schools. However, in a 3-level unconditional model, the ICCs representing the proportion of variance at the school level (Level 3) were all less than 0.003 , and most were less than 0.0001 , for all posttest variables. In addition, we reconducted all analyses adding school as a fixed effect at Level 2, and all results were unchanged from those in the models without school. Therefore, we dropped Level 3 for parsimony.

\section{Results}

\subsection{Descriptive statistics}

In the full sample, the 413 retained children differed from the 30 lost to attrition in that the retained children received more positive sociometric nominations, $t(441)=2.65, p=.008$, and fewer negative nominations, $t(441)=-2.72, p=.007$, at pretest; however, they were not different on any other variable. In the target sample, the 83 retained children differed from the eight lost to attrition only in that they received fewer negative nominations at pretest, $t(82)=-3.13, p=.002$.

Table 1 displays the means and standard deviations of study variables. At pretest there were no differences between intervention and comparison children in terms of demographics, negative nominations received, negative nominations expected, positive nominations expected, self-perceived peer acceptance, and teacher organization, in either the full sample or the sample of target children. However, at pretest comparison group children in the full sample received fewer positive nominations than did intervention group children $t(441)=-4.72, p<.001$, but reported greater teacher warmth than did intervention group children $t(437)=5.16$, $p<.001$. There were no differences in positive nominations or teacher warmth between target children in the intervention and comparison samples at pretest.

\begin{tabular}{|c|c|c|c|c|c|c|c|c|c|c|c|c|c|c|}
\hline & 1 & 2 & 3 & 4 & 5 & 6 & 7 & 8 & 9 & 10 & 11 & 12 & 13 & 14 \\
\hline 1. PNR-Pre & - & .17 & $-.39 * * *$ & $-.35^{* * *}$ & -.07 & -.07 & -.16 & $-.22 *$ & .13 & .01 & .05 & .06 & -.03 & .10 \\
\hline 2. PNR-Post & $.44 * * *$ & - & -.08 & $-.32^{* * *}$ & -.12 & .18 & -.12 & -.06 & -.06 & -.07 & $.26^{*}$ & -.03 & $.22^{*}$ & -.01 \\
\hline 3. NNR-Pre & $-.46 * * *$ & $-.38 * * *$ & - & $.32^{* * *}$ & .03 & .01 & .16 & .02 & -.10 & -.01 & -.16 & -.08 & -.04 & -.03 \\
\hline 4. NNR-Post & $-.41 * * *$ & $-.33 * * *$ & $.49 * * *$ & - & .11 & .07 & $.28 *$ & $.26^{*}$ & .06 & -.01 & -.05 & $-.23^{*}$ & -.21 & -.19 \\
\hline 5. PNE-Pre & .09 & .05 & -.01 & .04 & - & .19 & -.01 & .18 & .14 & .07 & -.05 & -.01 & -.04 & -.10 \\
\hline 6. PNE-Post & .09 & $.28 * * *$ & $-.14 * *$ & .01 & $.21 * * *$ & - & .07 & $.39 * * *$ & .04 & .04 & .20 & -.16 & .15 & -.17 \\
\hline 7. NNE-Pre & $-.13^{* *}$ & -.08 & $.21^{* * *}$ & $.22^{* * *}$ & $.21^{* * *}$ & .05 & - & .19 & .06 & -.01 & $-.28^{*}$ & -.06 & -.15 & -.05 \\
\hline 8. NNE-Post & $-.20 * * *$ & .01 & .04 & $.26^{* * *}$ & $.13^{* *}$ & $.22^{* * *}$ & $.17 * * *$ & - & -.02 & -.14 & .07 & $-.22 *$ & -.09 & $-.29 * *$ \\
\hline 9. PAcc-Pre & $.12 *$ & $.11^{*}$ & $-.13^{* * *}$ & -.02 & $.17^{* * *}$ & .08 & .07 & .01 & - & $.26 *$ & -.06 & $.23^{*}$ & .09 & .17 \\
\hline 10. PAcc-Post & $.11^{*}$ & .06 & -.02 & -.05 & $.12^{*}$ & $.12^{* *}$ & .06 & $-.22 * * *$ & $.26 * * *$ & - & .01 & .03 & .16 & $.25 *$ \\
\hline 11. TWar-Pre & .03 & $.12^{*}$ & -.08 & .01 & -.01 & -.02 & -.09 & $.10 *$ & -.02 & -.04 & - & .03 & $.56^{* * *}$ & .01 \\
\hline 12. TWar-Post & $.12^{*}$ & .06 & $-.13^{* * *}$ & $-.20 * * *$ & .04 & -.02 & .01 & $-.20 * * *$ & .04 & .08 & .05 & - & .11 & $.54 * * *$ \\
\hline 13. TOrg-Pre & .01 & .07 & -.01 & -.03 & .01 & -.03 & -.04 & $-.11^{*}$ & .02 & .01 & $.33^{* * *}$ & $.12^{*}$ & - & .16 \\
\hline 14. TOrg-Post & $.10^{*}$ & .04 & -.06 & $-.15^{* * *}$ & -.01 & -.04 & .02 & $-.20 * * *$ & $.12^{*}$ & $.18^{* * *}$ & .05 & $.57^{* * *}$ & .09 & - \\
\hline
\end{tabular}

Table 2 contains the bivariate correlation matrix. Most study variables had moderate stability between pretest and posttest time

Table 2

Correlations between study variables.

Note. Values for target children are above the diagonal and values for the full sample are below the diagonal. Pre $=$ Pretest assessment; Post $=$ Posttest assessment. PNR $=$ Positive nominations received; NNR $=$ Negative nominations received; PNE $=$ positive nominations expected; $\mathrm{NNE}=$ Negative nominations expected; PAcc $=$ Self-perceived peer acceptance; TWar $=$ Teacher warmth; TOrg = Teacher organization. ${ }^{*} p<.05 ;{ }^{* *} p<.01 ;{ }^{* *} p<.001$. 


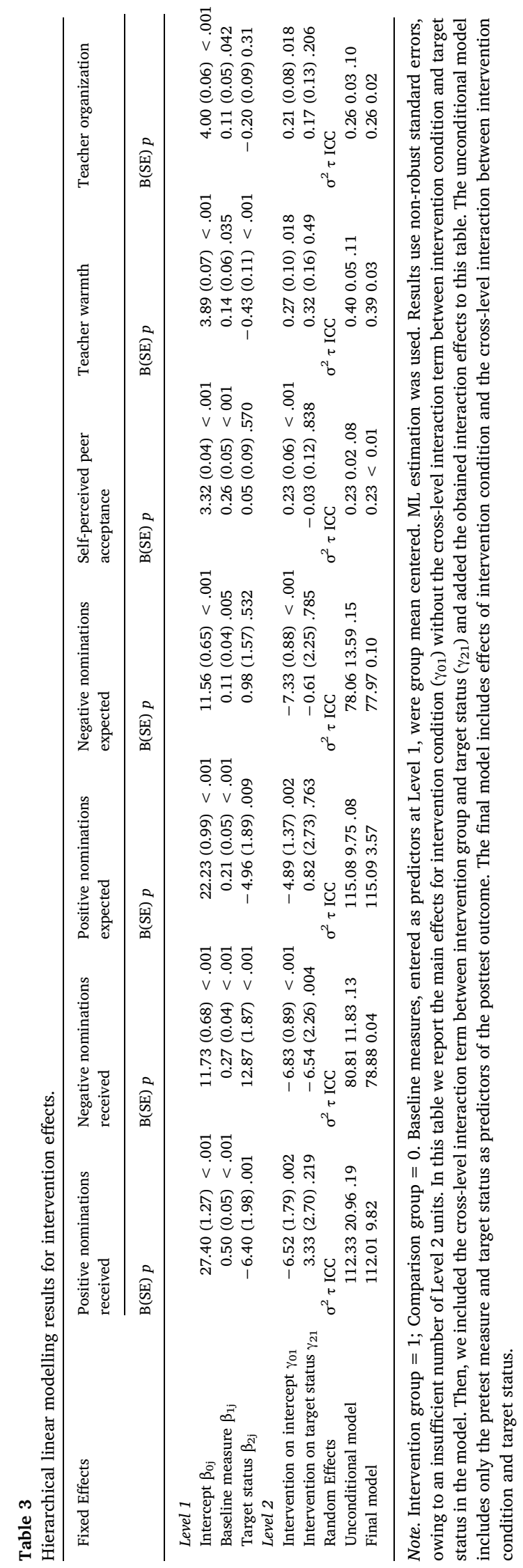


points, with the exception of students' perceptions of the teacher-student relationship. There were also modest, but significant, correlations between sociometric nominations received and expected, as well as between positive nominations and negative nominations. This demonstrates that these constructs are not simply redundant with each other.

\subsection{Differences between intervention and comparison groups}

Table 3 displays the HLM analyses examining intervention versus comparison group differences on the two primary and five secondary outcome variables, and moderation of intervention effects by target child status.

Sociometric nominations received (primary outcomes). Children in the intervention condition received fewer negative sociometric nominations from peers at posttest, after accounting for nominations received at pretest, relative to children in the comparison condition $(\mathrm{B}=-6.83 ; p<001)$. Target children also received more negative sociometric nominations at posttest after accounting for this variable at pretest $(\mathrm{B}=12.87 ; p<.001)$. $\mathrm{I}^{*}$ ever, the cross-level interaction between intervention condition and target student status was significant $(\mathrm{B}=-6.54 ; p<001, \overline{\bar{c} 11}$ : h that the efficacy of receiving the GREI intervention on fewer negative nominations received was stronger for target than for non-target children. For the purpose of illustrating this interaction effect, simple slopes analyses suggested that in the target sample, receiving the GREI intervention was associated with a stronger decrease in negative nominations received at posttest $(\mathrm{B}=-12.42 ; p<.001)$ relative to in the non-target sample $(\mathrm{B}=-6.05$; $p<.001)$. The addition of intervention condition and the interaction between intervention condition and target status in the final model almost completely explained the level 2 variance ( $99 \%$ reduction in variance) in the outcome measure of negative sociometric nominations received at posttest, relative to the unconditional model.

Children in the intervention condition also received fewer positive sociometric nominations from peers at posttest, after accounting for sociometric nominations received at pretest, relative to those in the comparison condition $(\mathrm{B}=-6.52 ; p=.002)$. Although being a target student was associated with receiving fewer positive nominations $(\mathrm{B}=-6.40 ; p=.001)$, target student status did not moderate the effect of intervention condition on this outcome $(\mathrm{B}=3.33 ; p=219)$. Including predictors was associated with a $53 \%$ reduction in Level 2 variance in positive nominations received.

Self-perceptions of peer relationships (secondary outcomes). Children in the intervention group expected to receive fewer negative sociometric nominations $(\mathrm{B}=-7.33 ; p=<.001)$, expected to receive fewer positive sociometric nominations $(\mathrm{B}=-4.89 ; p=.002)$, and reported higher self-perceptions of peer acceptance at posttest $(\mathrm{B}=0.23 ; p<.001)$, after accounting for these variables at pretest, relative to the comparison group. Target children did not differ from non-target children on their perceptions of negative nominations received or peer acceptance $(\mathrm{B}=0.98 ; p=.532$ and $\mathrm{B}=0.05 ; p=.570$, respectively), but they did expect to receive fewer positive nominations than nontarget children $(\mathrm{B}=-4.96 ; p=.009)$. However, target status did not moderate the effects of the intervention on any of these outcomes (negative nominations expected: $\mathrm{B}=-0.61 ; p=.785$, positive nominations expected: $\mathrm{B}=0.082 ; p=.763$, self-perceived peer acceptance: $\mathrm{B}=-0.03 ; p=838$ ). The inclusion of predictors was associated with reductions of $99 \%, 63 \%$, and $78 \%$ in the Level 2 variance of the outcome measures of negative nominations expected, positive nominations expected, and self-perceived peer acceptance, respectively.

Teacher-student relationships (secondary outcomes). Intervention group children reported that their teachers displayed more warmth $(\mathrm{B}=0.27 ; p=.18)$ and more organization $(\mathrm{B}=0.21 ; p=.018)$ at posttest, after accounting for these variables at pretest, relative to comparison group children. Target children reported teachers to have less warmth $(\mathrm{B}=-0.43 ; p<.001)$ and less organization $(\mathrm{B}=-0.20 ; p=.31)$ compared to non-target children. The cross-level interaction between intervention condition and target status was significant for the outcome of teacher warmth $(\mathrm{B}=0.32 ; p=.049)$, finding that the intervention resulted in greater perceptions of teacher warmth for target children compared to for non-target children. Again, to illustrate this interaction effect, simple slopes analyses suggested that in the target sample, receiving the GREI intervention was associated with a stronger increase in perceived teacher warmth $(\mathrm{B}=0.579 ; p=.002)$ relative to in the non-target sample $(\mathrm{B}=0.245 ; p=.001)$. There was no interaction between intervention condition and target status for teacher organization $(\mathrm{B}=0.17 ; p=.206)$. Including all predictors in the final model was associated with reductions of $37 \%$ in the Level 2 variance in teacher warmth, and $38 \%$ of the Level 2 variance in teacher organization, at posttest relative to the unconditional model.

\subsection{Clinical significance}

As an indicator of the clinical significance of these findings, we examined the posttest sociometric status for the 84 target children who received targeted intervention components because they were classified as rejected using the sociometric procedure. (For simplicity, we omitted the seven children who were nominated by teachers to be targets, but did not have rejected status). In the comparison group, 40 of the rejected target children had posttest data and 17 of them normalized (42\%), meaning that they became average or preferred at the posttest assessment point. In the intervention group, 36 of the rejected target children had posttest data and the corresponding figure was $22(61 \%)$ classified as average or preferred at posttest, $\chi^{2}(\mathrm{df}=1)=2.627 ; p=.105$.

\section{Discussion}

This manuscript presents the preliminary effects of the GREI intervention, a multi-component and multi-agent program to enhance positive classroom social relationships among early elementary school age children in Spain. Children were followed over the 1st through 2nd grade using a quasi-experimental, staggered implementation design where children in the comparison sample entered the study a year before children in the intervention sample. We found that children who received intervention displayed better 
outcomes in terms of receiving less disliking from peers, expecting to receive less disliking from peers, and reporting higher overall self-perceptions of peer acceptance as well as more positive relationships with teachers in terms of teacher warmth and organization. However, at the same time, intervention group children also received less peer liking, and expected to receive less liking from peers, relative to comparison group children. The beneficial effects of receiving the GREI intervention were stronger for target children (selected for being disliked by peers, who received augmented doses of the intervention) than for non-targets, in terms of less peer disliking received and children's perceptions of more teacher warmth.

\subsection{Peer relationships in intervention versus comparison samples}

Notably, intervention group children received significantly less peer disliking by the end of the 2nd grade year (posttest), after accounting for this same variable in the beginning of the 1st grade year (pretest), relative to the comparison sample. Although target children were at elevated risk compared to non-target children for peer disliking, the GREI intervention seemed to more strongly reduce peer disliking for target relative to non-target students. Children also perceived themselves to be less disliked by peers in the intervention relative to the comparison group. These self-perceptions lend support to the validity of the results from the peer reports. Further, they suggest that intervention group children may be aware that peers are disliking them less.

The consistent results for less peer disliking in the intervention group are promising because the negative adjustment consequences of being disliked are substantial, and perhaps stronger than any positive adjustment consequences of being liked (Parker et al., 2006). That is, it may be more critical, and more beneficial, to reduce peer disliking than it is to increase peer liking. Because the effects of being chronically disliked (e.g., year after year in elementary school) accumulate over time (Parker et al., 2006), the accentuated intervention effects on reducing peer disliking for target children may be particularly important for this vulnerable group. That children also seemed to be aware of their reductions in disliking in the intervention group is further encouraging, given evidence that self-perceptions of peer disliking incrementally exacerbate maladjustment (e.g., depression, negative social behaviors) above and beyond peers' actual reports (McElhaney, Antonishak, \& Allen, 2008).

Among target children in the intervention group with rejected status, $61 \%$ had become average or preferred by the posttest assessment (relative to $42 \%$ of target children in the comparison group). Although this was not a statistically significant difference, the direction of the effect suggests potentially lower stability of rejected status in the intervention group, such that students in these classrooms were more flexible than comparison children in changing their impressions about classmates. Related work has found that teachers who were observed to demonstrate warm, emotionally supportive practices also had classrooms where children showed lower stability of liking and disliking impressions across 1 school year (Mikami et al., 2012). Given the evidence that children possess cognitive biases that maintain the initial impressions they develop about classmates (Mikami \& Normand, 2015), we think this suggests some potential for the GREI intervention to reduce some of the typical rigidity of children's negative social judgments. An implication is that, in GREI intervention classrooms, there may be more potential for children who are initially peer-rejected to change in sociometric status over time.

On the other hand, the results for peer liking were contrary to hypotheses, in that intervention group children both received less liking from peers, and also expected to receive less peer liking. It is possible that the GREI intervention components better targeted the reduction in disliking as opposed to an increase in liking. These results also raise the possibility that the GREI intervention had an iatrogenic effect on reducing peer liking. Although post hoc, we speculate that perhaps the intervention activities may have made children more selective in the classmates they positively nominated. For example, the components to reduce prejudices may have made children more aware of the meaning of nominating a classmate as liked, such that they began to only do so if they felt a personal bond with them, as opposed to if they simply perceived the classmate to have high status in the group at large. If a result of the GREI intervention is that students become less swayed by reputational bias, this could also explain our finding that intervention group children named fewer classmates as "disliked" in addition to naming fewer classmates as "liked" (see, for instance, De Laet et al., 2014); we think this would reflect flexible thinking and overall be a benefit of the intervention.

Nonetheless, children showed higher self-perceived peer acceptance in the intervention group relative to the comparison group. This perhaps indicates that children's perceptions of their disliking by peers is more important than their perceptions of liking by peers in determining their feelings about whether they are included by peers overall. As such, it is possible that their expectations about receiving less peer liking do not carry much impact on their self-evaluations of peer acceptance.

\subsection{Teacher-student relationships in intervention versus comparison samples}

Children reported their teachers to show more warmth and better organization if they were in the intervention group as opposed to if they were in the comparison group. Interestingly, examination of group means suggests that children in both intervention and comparison classrooms reported positive relationships with their teachers at pretest, but these perceptions declined over the study period for comparison children but not intervention children. This perhaps suggests that the GREI intervention is associated with preventing a natural deterioration in teacher-student relationships found as children progress through elementary school (Collins, Andrew, O'Connor, Supplee, \& Shaw, 2017). Although we did not have observational measures of teacher-student relationship quality to lend validity to student reports, children likely had limited awareness that improving the teacher-student relationship was an intervention goal, and felt few social desirability pressures to give positive responses about intervention group teachers. That the effect of intervention for greater teacher warmth was augmented for the target children is additionally encouraging, because children who are disliked by peers are most likely to have poor relationships with teachers in addition to their peer difficulties, but teacherstudent relationships influence peers' perceptions of these children (Hughes \& Im, 2016). 


\subsection{Study strengths and limitations}

One strength of this study is the comprehensive, multi-component nature of the GREI intervention in which we acknowledged the complexity of classroom social relationships by intervening through multiple channels using multiple agents. Indeed, we attempted to address four focus areas thought to contribute to classroom relationships. Each intervention strategy also had at least some empirical support in previous work when used alone. The inclusion of both universal intervention components as well as more intensive efforts directed at target children with peer problems was another strength indicating the thorough nature of our approach.

In addition, this study relied upon peer sociometric nominations as the primary outcome measure supplemented by children's selfreports of their perceived relationships with peers and teachers. Although we did not have observational measures of teacher-student interactions, we think our measurement strategy has strengths relative to studies that predominantly or exclusively rely upon teacher report to assess intervention effects (when teachers have delivered the intervention, and also may not be privy to children's liking and disliking of one another).

Nonetheless, this study possesses several limitations. Most notably, classrooms were not randomly assigned to intervention versus comparison groups. The staggered implementation design, whereby all 1st grade students in the first year of the study became the comparison group, and then all 1st grade students in the second year of the study (in the same four schools) became the intervention group, potentially helped to equate demographic factors across groups. Indeed, at pretest, intervention and comparison groups did not differ on any demographic measures or on most study outcome measures. Still, this was not random assignment, and the quasiexperimental design leaves open the possibility that unmeasured characteristics may have affected the results instead of, or in addition to, the GREI intervention provision. For example, there were more male teachers in the comparison sample than in the intervention sample and, although this was not a statistically significant difference, this may have influenced study results.

Another significant limitation concerns our measurement of implementation fidelity. Teachers reported on their use of the intervention components to the consultant, but we had no independent observations of this construct. Relatedly, we also had no measures of potential contamination between intervention and comparison group teachers. Although teachers reported high use of and satisfaction with the intervention, and our perception (from the consultation meetings) is that implementation was high, explaining variability in implementation fidelity is a priority for future work. Further, it was not possible to determine which individual intervention component or components may have been driving results. Better tracking of implementation fidelity would have allowed us to assess change in outcome measures as a function of variability in implementation of each intervention component. Nonetheless, we view this preliminary study as following an intent-to-treat model, such that we attempted to evaluate intervention effects independent of the actual doses of intervention received.

Finally, although attrition was overall low, there were indications that retained children had better sociometric functioning. An implication is that findings from the current study may not be applicable to the children who are most socially impaired. However, the effect of the intervention on less peer disliking was accentuated among target students (selected for having peer problems), so it is possible that the intervention would have been helpful for the students who were lost to attrition.

\subsection{Implications for practice}

These findings support the utility of school-based strategies to reduce children's negative sociometric impressions of classmates (with the caveat that the intervention may also result in less sociometric liking as well as less disliking). Peer disliking has historically been quite intervention resistant, yet it relates to children's academic and behavioral adjustment in significant ways (Mikami \& Normand, 2015). A strength and a limitation of the GREI intervention is that it contained multiple components to address peer disliking comprehensively, over a period of 2 years. However, we do not know which components may be most responsible for any effects, or whether enacting some components but not others would still be efficacious. We also do not know if similar results could be achieved in a shorter amount of time. Like other peer relationships researchers (Parker et al., 2006), we speculate that the current level of intensity and comprehensiveness in our intervention is in fact what is needed to reduce peer disliking. Nonetheless, the comprehensive nature and length of the intervention may make it less feasible for teachers to deliver, unless they receive strong support from their school administration and/or school psychologists. This level of support may require systemic change whereby learning social-emotional skills is viewed as a process that takes repetition over years of schooling, similar to how learning reading or mathematics is viewed. We did create a training procedure and manuals for each intervention component. All materials have been given to the participating schools, and we hope that these will be helpful to educators and practitioners.

\section{Conclusions}

This study presented the preliminary evaluation of a multi-component and multi-agent intervention to improve the classroom social relationships of Spanish children over their 1st and 2nd grade years. Most results from this quasi-experimental design suggested that the GREI intervention had beneficial effects. Children who received the intervention were less disliked by classmates, expected to be less disliked by classmates and perceived themselves to be more peer-accepted, and reported their teachers to have more warmth and organization, relative to those in the comparison condition. Further, the association between the intervention and less peer disliking as well as more teacher warmth was accentuated among the at-risk group of target children with peer problems. However, children who received the intervention also received less peer liking from classmates and expected to receive less peer liking. Although the possibility of iatrogenic effects associated with the intervention on peer liking is a concern, we are encouraged by the reductions in peer disliking (objectively received and self-perceived), as persistent disliking carries adjustment consequences - 
indeed, perhaps more serious than does potential benefits from being liked. The accentuated benefits in reduced peer disliking for the most at-risk children, the target sample, is additionally encouraging. Future research might test the strategy of addressing multiple contributors to classroom social relationships with multiple agents, to acknowledge the complexity of this construct.

\section{Acknowledgement}

This research was supported by grant EDU2012-35930 from the Spanish Ministry of Economy and Competitiveness and grant P11A2012-04 from the Universitat Jaume I. We thank all the teachers, students, and families for their participation in this research.

\section{References}

Bar-On, R. (2006). The Bar-On Model of emotional-social intelligence. Psicothema, 18, 13-25.

Bellmore, A. D., \& Cillesen, A. H. N. (2003). Children's meta-perceptions and meta-accuracy of acceptance and rejection by same-sex and other-sex peers. Personal Relationships, 10, 217-233. https://doi.org/10.1111/1475-6811.00047.

van den Berg, Y. H., \& Stoltz, S. (2018). Enhancing social inclusion of children with externalizing problems through classroom seating arrangements: A randomized controlled trial. Journal of Emotional and Behavioral Disorders, 1, 31-41. https://doi.org/10.1177/1063426617740561.

Bronfenbrenner, U. (1992). Ecological systems theory. In V. Ross (Ed.). Six theories of child development: Revised formulations and current issues (pp. 187-249). London, England: Jessica Kingsley Publishers.

Buhs, E. S., Ladd, G. W., \& Herald, S. L. (2006). Peer exclusion and victimization: Processes that mediate the relation between peer group rejection and children's classroom engagement and achievement? Journal of Educational Psychology, 98, 1-13. https://doi.org/10.1037/0022-0663.98.1.1.

Chang, L. (2004). The role of classroom norms in contextualizing the relations of children's social behaviors to peer acceptance. Developmental Psychology, 40, 691-702. https://doi.org/10.1037/0012-1649.40.5.691.

Cillessen, A. H. N., \& Bukowski, W. M. (2018). Sociometric perspectives. In W. M. Bukowski, B. Laursen, \& K. H. Rubin (Eds.). Handbook of peer interactions, relationships, and groups (pp. 63-84). (2nd ed.). New York: Guilford.

Coie, J. D., Dodge, K. A., \& Coppotelli, H. (1982). Dimensions and types of social status: A cross-age perspective. Developmental Psychology, 18, 557-570. https://doi. org/10.1037/0012-1649.18.4.557.

Collins, B., Andrew, O'Connor, E. E., Supplee, L., \& Shaw, D. S. (2017). Behavior problems in elementary school among low-income boys: The role of teacher-child relationships. The Journal of Educational Research, 110, 72-84. https://doi.org/10.1080/00220671.2015.1039113.

Conduct Problems Prevention Research Group (1999a). Initial impact of the fast track prevention trial for conduct problems I: The high-risk sample. Journal of Consulting and Clinical Psychology, 67, 631-647.

Conduct Problems Prevention Research Group (1999b). Initial impact of the fast track prevention trial for conduct problems II: Classroom effects. Journal of Consulting and Clinical Psychology, 67, 648-657.

Conduct Problems Prevention Research Group (2002). Evaluation of the first 3 Years of the Fast Track Prevention Trial with children at high risk for adolescent conduct problems. Journal of Abnormal Child Psychology, 30, 19-35. https://doi.org/10.1023/a:1014274914287.

De Laet, S., Doumen, S., Vervoort, E., Colpin, H., Van Leeuwen, K., Goossens, L., et al. (2014). Transactional links between teacher-child relationship quality and perceived versus sociometric popularity: A three wave longitudinal study. Child Development, 85, 1647-1662.

Durlak, J. A., Weissberg, R. P., Dymnicki, A. B., Taylor, R. D., \& Schellinger, K. B. (2011). The impact of enhancing students' social and emotional learning: A metaanalysis of school-based universal interventions. Child Development, 82, 405-432. https://doi.org/10.1111/j.1467-8624.2010.01564.x.

El Nokali, N. E., Bachman, H. J., \& Votruba-Drzal, E. (2010). Parent involvement and children's academic and social development in elementary school. Child Development, 81, 988-1005. https://doi.org/10.1111/j.1467-8624.2010.01447.x.

Farmer, T. W., Lines, M. M., \& Hamm, J. V. (2011). Revealing the invisible hand: The role of teachers in children's peer experiences. Journal of Applied Developmental Psychology, 32, 247-256. https://doi.org/10.1016/j.appdev.2011.04.006.

Forest, C., \& García Bacete, F. J. (2006). Comunicación cooperativa entre la familia y la escuela. Valencia: Edicions Culturals Valencianes, S.A.

García Bacete, F. J., Carrero, V. E., Marande, G., \& Musitu, G. (2017). Understanding rejection between first and second grade elementary students through reasons expressed by rejecters. Frontiers in Psychology, 8, 1-13. https://doi.org/10.3389/fpsyg. 2017.00462.

García Bacete, F. J., \& Cillessen, A. H. N. (2017). An adjusted probability method for the identification of sociometric status in classrooms. Frontiers in Psychology, 8. https://doi.org/10.3389/fpsyg.2017.01836.

García Bacete, F. J., Marande, G., Ferrá, P., \& Monjas, M. I. (2014). Teacher-student relationships in first and second grade classrooms. Adaptation of the questionnaire on Teacher Interaction-Early Primary (QTI-EP). Revista de Psicodidáctica, 19, 211-231. https://doi.org/10.1387/RevPsicodidact.9081.

García Bacete, F. J., Marande, G., Schneider, B. H., \& Cillessen, A. H. N. (2019). Children's awareness of peer rejection and teacher reports of aggressive behavior. Psychosocial Intervention, 28, 37-47. https://doi.org/10.5093/pi2018a25.

García Bacete, F. J., Rubio, A., Milián, I., \& Marande, G. (2013). El aprendizaje de la amistad en la educación primaria. Un procedimiento intensivo para ayudar a los niños rechazados a hacer amigos. Apuntes de Psicología, 31, 155-163.

Gifford-Smith, M. E., \& Brownell, C. A. (2003). Childhood peer relationships: Social acceptance, friendships, and peer networks. Journal of School Psychology, 41, 235-284.

González, J., \& García Bacete, F. J. (2010b). Sociomet. Programa para la realización de estudios sociométricos. Madrid, Spain: TEA Ediciones.

González, J., \& García Bacete, F. J. (2010a). Manual de Uso del Sociomet. Madrid: TEA Ediciones.

Harrist, A. W., \& Bradley, K. D. (2003). "You can't say you can't play": Intervening in the process of social exclusion in the kindergarten classroom. Early Childhood Research Quarterly, 18, 185-205. https://doi.org/10.1016/s0885-2006(03)00024-3.

Harter, S., \& Pike, R. (1984). The pictorial scale of perceived competence and social acceptance for young children. Child Development, 55, 1969-1982. https://doi.org/ $10.2307 / 1129772$.

Hendrickx, M. M. H. G., Mainhard, T., Oudman, S., Boor-Klip, H. J., \& Brekelmans, M. (2017). Teacher behavior and peer liking and disliking: The teacher as a social referent for peer status. Journal of Educational Psychology, 109, 546-558. https://doi.org/10.1037/edu0000157.

Hughes, J. N., \& Chen, Q. (2011). Reciprocal effects of student-teacher and student-peer relatedness: Effects on academic self efficacy. Journal of Applied Developmental Psychology, 32, 278-287. https://doi.org/10.1016/j.appdev.2010.03.005.

Hughes, J. N., \& Im, M. H. (2016). Teacher-student relationship and peer disliking and liking across grades 1-4. Child Development, 87, 593-611. https://doi.org/10. $1111 /$ cdev.12477.

Hughes, J., \& Kwok, O.-m. (2007). Influence of student-teacher and parent-teacher relationships on lower achieving readers' engagement and achievement in the primary grades. Journal of Educational Psychology, 99, 39-51. https://doi.org/10.1037/0022-0663.99.1.39.

January, A. M., Casey, R. J., \& Paulson, D. (2011). A meta-analysis of classroom-wide interventions to build social skills: Do they work? School Psychology Review, 40, $242-256$.

Kagan, S., \& Kagan, M. (2009). Kagan's cooperative learning. San Clemente: Kagan Publishing.

Karcher, M. (2007). Pair counseling: A developmental intervention for counseling children in dyads. Unpublished manual, University of Texas at San Antonio.

Kaufman, T. M. L., Kretschmer, T., Huitsing, G., \& Veenstra, R. (2019). Why does a universal anti-bullying program not help all children? Explaining persistent victimization during an intervention. Prevention Science. https://doi.org/10.1007/s11121-018-0906-5.

Korpershoek, H., Harms, T., de Boer, H., van Kuijk, M., \& Doolaard, S. (2016). A meta-analysis of the effects of classroom management strategies and classroom 
management programs on students' academic, behavioral, emotional, and motivational outcomes. Review of Educational Research, 86, 643-680. https://doi.org/10. 3102/0034654315626799.

Levin, J., \& Nolan, J. F. (2014). Principles of classroom management: A professional decision-making model (7th ed.). Upper Saddle River, New Jersey: Pearson Education. McDowell, D. J., \& Parke, R. D. (2009). Parental correlates of children's peer relations: An empirical test of a tripartite model. Developmental Psychology, 45, 224-235. https://doi.org/10.1037/a0014305.

McElhaney, K. B., Antonishak, J., \& Allen, J. P. (2008). "They like me, they like me not": Popularity and adolescents' perceptions of acceptance predicting social functioning over time. Child Development, 79, 720-731. https://doi.org/10.1111/j.1467-8624.2008.01153.x.

Mikami, A. Y., Griggs, M. S., Lerner, M. D., Emeh, C. C., Reuland, M. M., Jack, A., et al. (2013). A randomized trial of a classroom intervention to increase peers' social inclusion of children with Attention-Deficit/Hyperactivity Disorder. Journal of Consulting and Clinical Psychology, 81, 100-112. https://doi.org/10.1037/ a0029654.

Mikami, A. Y., Griggs, M. S., Reuland, M. M., \& Gregory, A. (2012). Teacher practices as predictors of children's classroom social preference. Journal of School Psychology, 50, 95-111. https://doi.org/10.1016/j.jsp.2011.08.002.

Mikami, A. Y., Lerner, M. D., Griggs, M. S., McGrath, A., \& Calhoun, C. D. (2010). Parental influence on children with attention-deficit/hyperactivity disorder: II. Results of a pilot intervention training parents as friendship coaches for children. Journal of Abnormal Child Psychology, 38, 737-749. https://doi.org/10.1007/ s10802-010-9403-4.

Mikami, A. Y., \& Mercer, S. H. (2017). Teacher behaviors toward children with Attention-Deficit/Hyperactivity Disorder predict peers' initial liking and disliking impressions in a summer camp setting. Journal of Social and Clinical Psychology, 36, 506-534.

Mikami, A. Y., \& Normand, S. (2015). The importance of social contextual factors in peer relationships of children with ADHD. Current Developmental Disorders Reports, $2,30-37$.

Morrison, J. Q., \& Jones, K. M. (2007). The effects of positive peer reporting as a class-wide positive behavior support. Journal of Behavioral Education, 16, 111-124. https://doi.org/10.1007/s10864-006-9005-y.

National Assocation of School Psychologists (2016). NASP position statement: Integrated model of academic and behavior supports. Retrieved August 31 2018, from http:// www.nasponline.org/research-and-policy/professional-positions/position-statements.

Parker, J. G., Rubin, K. H., Erath, S. A., Wojslawowicz, J. C., \& Buskirk, A. A. (2006). Peer relationships, child development, and adjustment: A developmental psychopathology perspective. In (2nd ed.). D. Cicchetti, \& D. J. Cohen (Vol. Eds.), Developmental psychopathology: Vol. 1, (pp. 419-493). Hoboken, NJ: John Wiley \& Sons.

Peets, K., Hodges, E. V. E., \& Salmivalli, C. (2008). Affect-congruent social-cognitive evaluations and behaviors. Child Development, 79, 170-185. https://doi.org/10 $1111 /$ j.1467-8624.2007.01118.x.

Pianta, R. C., \& Stuhlman, M. W. (2004). Teacher-child relationships and children's success in the first years of school. School Psychology Review, 33, 444.

Pujolàs, P. (2008). Nueve ideas clave: El aprendizaje cooperativo. Barcelona: Grao.

Raudenbush, S. W., \& Bryk, A. S. (2002). Hierarchical linear models: Applications and data analysis methods (2nd ed.). Thousand Oaks, CA: Sage Publications.

Rose-Krasnor, L., \& Denham, S. (2009). Social-emotional competence in early childhood. In K. H. Rubin, W. M. Bukowski, \& B. Laursen (Eds.). Handbook of peer interactions, relationships and groups (pp. 162-179). New York: Guilford.

Roseth, C. J., Johnson, D. W., \& Johnson, R. T. (2008). Promoting early adolescents' achievement and peer relationships: The effects of cooperative, competitive, and individualistic goal structures. Psychological Bulletin, 134, 223-246. https://doi.org/10.1037/0033-2909.134.2.223.

Sheridan, S. M., \& Kratochwill, T. R. (2007). Conjoint behavioral consultation: Promoting family-school connections and interventions. New York: Springer Science \& Business Media.

Wubbels, T. (2011). An international perspective on classroom management: What should prospective teachers learn? Teaching Education, 22, 113-131. https://doi. org/10.1080/10476210.2011.567838.

Zijlstra, H., Wubbels, T., Brekelmans, M., \& Koomen, H. (2013). Child perceptions of teacher interpersonal behavior and associations with mathematics achievement in Dutch early grade classrooms. The Elementary School Journal, 113, 517-540. https://doi.org/10.1086/669618. 